\title{
Development of a core set of outcome measures for OAB treatment
}

\author{
Caroline Foust-Wright ${ }^{1,2} \cdot$ Stephanie Wissig $^{2}$ - Caleb Stowell ${ }^{2}$. Elizabeth Olson ${ }^{2}$. \\ Anita Anderson - Jennifer Anger ${ }^{3}$ - Linda Cardozo ${ }^{4}$. Nikki Cotterill ${ }^{5}$. \\ Elizabeth Ann Gormley $^{6}$ • Philip Toozs-Hobson ${ }^{7}$ • John Heesakkers ${ }^{8}$ - Peter Herbison ${ }^{9}$. \\ Kate Moore $^{10}$. Jessica McKinney ${ }^{11}$ - Abraham Morse ${ }^{12}$. Samantha Pulliam ${ }^{13}$. \\ George Szonyi $^{14}$ - Adrian Wagg ${ }^{15} \cdot \operatorname{Ian}_{\text {Milsom }^{16}}$ (D)
}

Received: 17 April 2017 / Accepted: 6 September 2017 / Published online: 25 September 2017

(C) The Author(s) 2017. This article is an open access publication

\begin{abstract}
Introduction and hypothesis Standardized measures enable the comparison of outcomes across providers and treatments giving valuable information for improving care quality and efficacy. The aim of this project was to define a minimum standard set of outcome measures and case-mix factors for evaluating the care of patients with overactive bladder $(\mathrm{OAB})$. Methods The International Consortium for Health Outcomes Measurement (ICHOM) convened an international working group (WG) of leading clinicians and patients to engage in a
\end{abstract}

Electronic supplementary material The online version of this article (https://doi.org/10.1007/s00192-017-3481-6) contains supplementary material, which is available to authorized users.

Ian Milsom

ian.milsom@gu.se

1 Department of Obstetrics and Gynecology, Division of Female Pelvic Medicine and Reconstructive Surgery, Massachusetts General Hospital, Boston, MA, USA

2 International Consortium for Health Outcomes Measurement, Cambridge, MA, USA

3 Department of Urologic Reconstruction, Urodynamics, and Female Urology, Department of Surgery, Division of Urology, Cedars-Sinai Medical Center, Los Angeles, CA, USA

4 Department of Urogynaecology, King's College Hospital, London, UK

5 Bristol Urological Institute, Southmead Hospital, Bristol, UK

6 Section of Urology, Department of Surgery, Dartmouth-Hitchcock Medical Center, Lebanon, NH, USA

7 Birmingham Women's NHS Foundation Trust, Birmingham, UK

8 Department of Urology, Radboud University Medical Center, Nijmegen, The Netherlands

structured method for developing a core outcome set. Consensus was determined by a modified Delphi process, and discussions were supported by both literature review and patient input.

Results The standard set measures outcomes of care for adults seeking treatment for $\mathrm{OAB}$, excluding residents of long-term care facilities. The WG focused on treatment outcomes identified as most important key outcome domains to patients: symptom burden and bother, physical functioning, emotional health, impact of symptoms and treatment on quality of life, Zealand

10 Department of Urogynaecology, University of New South Wales, Sydney, NSW, Australia

11 Center for Pelvic and Women's Health, Marathon Physical Therapy and Sports Medicine, LLC, Norton, MA, USA

12 Department of Obstetrics and Gynecology, Guangzhou Women and Children's Medical Center, Guangzhou, China

13 Division of Urogynecology and Reconstructive Pelvic Surgery, Department of Obstetrics and Gynecology, University of North Carolina, Chapel Hill, NC, USA

14 Department of Geriatric Medicine, Royal Prince Alfred Hospital, Sydney, Australia

15 Geriatric Medicine, University of Alberta, Edmonton, Canada

16 Department of Obstetrics \& Gynaecology, Institute of Clinical Sciences, Sahlgrenska Academy at Gothenburg University, Sahlgrenska University Hospital, SE-416 85 Gothenburg, Sweden 
and success of treatment. Demographic information and casemix factors that may affect these outcomes were also included. Conclusions The standardized outcome set for evaluating clinical care is appropriate for use by all health providers caring for patients with $\mathrm{OAB}$, regardless of specialty or geographic location, and provides key data for quality improvement activities and research.

Keywords Overactive bladder · Outcome measures .

Standard set

$\begin{array}{ll}\text { Abbreviations } \\ \text { OAB } & \text { Overactive bladder } \\ \text { ICHOM } & \begin{array}{l}\text { International Consortium for Health Outcomes } \\ \end{array} \\ \text { Measurement } \\ \text { WG } & \text { Working group } \\ \text { VBHC } & \text { Value-based health care } \\ \text { IUGA } & \text { International Urogynecology Association } \\ \text { ICS } & \text { International Continence Society } \\ \text { PTNS } & \begin{array}{l}\text { Posteroposterior percutaneous tibial nerve } \\ \text { stimulation }\end{array} \\ \text { SNS } & \text { Sacral neuromodulation }\end{array}$

\section{Introduction}

Overactive bladder $(\mathrm{OAB})$ is a symptom-based condition defined as urinary urgency, with or without urgency incontinence, usually accompanied by frequency and nocturia in the absence of urinary tract infections or other obvious pathology $[1,2]$. It is a common condition that affects many individuals worldwide, with a prevalence estimated between 11.8 and $17 \%$, with incidence increasing with increasing age. $\mathrm{OAB}$ negatively impacts quality of life $(\mathrm{QoL})$ and often results in significant healthcare expenditures [3-5]. Treatments range from conservative approaches, such as lifestyle intervention, to pharmacological and surgical options. For many patients, the process of seeking care involves frequent clinic appointments and multiple treatment approaches. A study of five European countries and Canada found that the annual expenditure per patient for $\mathrm{OAB}$ ranged from 262 to 619 euros (US\$293-693). When indirect costs such as work absenteeism were included, the total cost for the estimated 25 million people with $\mathrm{OAB}$ in the countries studied was 9.7 billion euros [6]. Despite the significant cost of OAB management, it is difficult to determine the most effective and efficient treatment approaches because there are no standard outcome metrics that allow comparison of outcomes and costs across providers.

The discipline of value-based health care (VBHC) contains the tools to support such a strategy [7]. VBHC defines "value" in healthcare as the ratio between the outcomes of care delivered and the cost of achieving those outcomes. The VBHC agenda focuses on the standardization of metrics to promote comparison of outcomes and costs across providers for identifying best practices for delivering high-value care [8]. Standardized measures enable comparison of outcomes across providers and treatments to improve care quality and efficacy. Measures for evaluating care outcomes for $\mathrm{OAB}$ that are most important to patients would be of great utility to improve our understanding of which treatment options or combinations offer greatest treatment value.

The International Consortium for Health Outcomes Measurement (ICHOM) is a not-for-profit organization that convenes international working groups of clinicians, researchers, and patients to define minimum sets of standardized outcomes by medical condition with a focus on outcomes that matter most to patients (www.ichom.org). Following such development, ICHOM works to support implementation and benchmarking of these standard sets to facilitate the adoption of VBHC worldwide. The objective of this project was to define a minimum standard set of outcomes for evaluating $\mathrm{OAB}$ treatment. This set of outcome measures and case-mix factors is designed to be appropriate for and easily implemented by any clinician treating patients with $\mathrm{OAB}$, regardless of medical specialty, treatment given, or country of practice.

\section{Methods}

\section{Working group}

ICHOM convened an international working group (WG) of clinicians, researchers, and patients who are experts in treating $\mathrm{OAB}$. Members were selected via review of the literature and consultation with leaders in the field to provide global representation across the key clinical disciplines involved, including urology, urogynecology, geriatrics, and pelvic floor physical therapy (Table 1). The WG was led by a project team composed of an ICHOM standardization director (SW), coleads (AW and IM), and research fellow (CF). All members were physicians, three routinely treated patients with $\mathrm{OAB}$ (AW, IM, CF), and all volunteered their time for the project. The standardization director and research fellow were employed by ICHOM. Funding for the project was provided by the International Urogynecology Association (IUGA). To better understand which outcome domains matter most to patients, the project team invited a patient representative to the WG and held patient-group discussions.

\section{Standard set scope}

The WG decided that the standard set would apply to outcomes of care for all adult patients diagnosed with idiopathic OAB, excluding residents of long-term care facilities, and 
Table 1 Working group members by country and specialty, including organizations and specialty societies represented

\begin{tabular}{|c|c|c|c|c|}
\hline Country & Specialty & Working group member & Organization & Specialty society \\
\hline \multirow[t]{2}{*}{ Australia } & \multirow[t]{2}{*}{ Geriatric medicine } & George Szonyi & Royal Prince Alfred Hospital & CFA \\
\hline & & Kate Moore & $\begin{array}{l}\text { School of Women's and Children's } \\
\text { Health, University of New South } \\
\text { Wales }\end{array}$ & ICS, CFA \\
\hline Canada & Geriatric medicine & Adrian Wagg & University of Alberta & ICS ICI \\
\hline The Netherlands & Urology & John Heesakkers & Radboud University Medical Center & EAU (AUA, ICS, SUFU) \\
\hline New Zealand & Biostatistics & Peter Herbison & $\begin{array}{l}\text { Dunedin School of Medicine, Otago } \\
\text { University }\end{array}$ & Cochrane \\
\hline Sweden & Obstetrics and gynecology & Ian Milsom & Sahlgrenska Academy & EUGA, IUGA, ICS ICI \\
\hline \multirow[t]{7}{*}{ United States } & Obstetrics and gynecology & Caroline Foust-Wright & Massachusetts General Hospital & \\
\hline & Patient representative & Anita Anderson & & \\
\hline & Physical therapy & Jessica McKinney & $\begin{array}{l}\text { Marathon Physical Therapy \& Sports } \\
\text { Medicine, LLC. }\end{array}$ & \\
\hline & Urology & Jennifer Anger & University of California - Los Angeles & SUFU \\
\hline & \multirow[t]{3}{*}{ Urogynaecology } & Elizabeth Ann Gormley & Dartmouth-Hitchcock Medical Center & AUA, SUFU \\
\hline & & Abraham Morse & $\begin{array}{l}\text { Guangzhou Women and Children's } \\
\text { Medical Center }\end{array}$ & AUGS \\
\hline & & Samantha Pulliam & $\begin{array}{l}\text { University of North Carolina at } \\
\text { Chapel Hill }\end{array}$ & AUGS \\
\hline \multirow[t]{3}{*}{ United Kingdom } & Pelvic floor medicine & Philip Toozs-Hobson & $\begin{array}{l}\text { Birmingham Women's NHS Foundation } \\
\text { Trust }\end{array}$ & IUGA \\
\hline & Outcomes research & Nikki Cotterill & Bristol Urological Institute & ICI \\
\hline & Urogynaecology & Linda Cardozo & $\begin{array}{l}\text { King's College Hospital, National } \\
\text { Health Service (NHS) }\end{array}$ & $\begin{array}{l}\text { EUGA (IUGA), BSUG, } \\
\text { ICS, ICI }\end{array}$ \\
\hline
\end{tabular}

CFA Continence Foundation of Australia, ICS International Continence Society, EAU European Association of Urology, AUA American Urological Association, EUGA European Urogynaecology Assocation, IUGA International Urogynecological Association, SUFU Society of Urodynamics, Female Pelvic Medicine \& Urogenital Reconstruction, AUGS American Urogynecologic Society, ICI International Consultation on Incontinence, BSUG British Society of Urogynaecology

unanimously agreed to define OAB according to the International Continence Society (ICS)/IUGA definition. Treatment approaches included first-line interventions such as patient education and behavioral modification, bladder retraining, pharmacological management, onabotulinumtoxinA injection, posteroposterior percutaneous tibial nerve stimulation (PTNS), sacral neuromodulation (SNS), and surgery.

\section{Work process and decision making}

The measure set was developed using a modified Delphi process [9]. Between September 2015 and June 2016, the group convened for eight teleconferences. Each addressed a specific goal: establishing the scope of the measure set, defining the patient population, selecting the appropriate outcomes and case-mix domains, and defining the relevant metrics. For each topic, the project team reviewed the existing literature and current practices to develop proposals for discussion during the teleconference. Detailed minutes of these discussions were distributed to WG members, who then voted on each item presented in the proposals via an online survey. Individual proposal items required a $70 \%$ majority vote of survey respondents to be included in the measure set. Survey items with
$<70 \%$ approval were either excluded from the set or revised by the project team following comments and were again presented for discussion and voting at the next teleconference.

\section{Selection of outcome and case-mix domains}

Additional sources of information were sought to support the selection of outcome domains. A systematic literature review was performed to determine outcome domains currently used to evaluate OAB. PubMed was searched with the terms "overactive bladder" or "urinary bladder, overactive" or "lower urinary tract" combined with "patient outcome assessment" or "outcome assessment" or "treatment outcome(s)". Limits included full-text articles, humans, publication from 1 January /2000 to 31 December 2015, English language (due to the language limits of the team leadership), and data from earlier publications in the form of review articles and meta-analyses (complete description provided in Supplementary Material 1).

Structured patient group discussions were conducted to better understand what outcome domains mattered most to patients. We aimed to balance this group by age, parity, phase in the care cycle, clinical experience, and nationality. We 
recognize that this did not provide a fully representative sample of patients globally, however, our aim was to gather information to guide our work, not to publish definitive results. Specifically, patient groups were asked which outcomes were most important to them, had the most effect on day-to-day life, and if any domains were missing from those identified from the literature review.

A comprehensive list of potential outcome domains was identified from these sources and presented to the WG for discussion. WG members were asked to score each potential outcome on the Grades of Recommendation Assessment, Development and Evaluation (GRADE) scale [10]. Outcome domains scored as important (7-9) by at least 70\% of respondents were included in the set. Those scored as unimportant (1-3) by at least $70 \%$ of respondents were excluded. Those remaining were modified and represented for a second round of voting. Domains meeting neither inclusion nor exclusion criteria after a second round of voting were discussed again and then presented for a final binary vote.

Once outcome domains were identified, each was defined. All included domains were deemed appropriate for capture by patient report. Relevant patient-reported outcome measures (PROMs) were then identified from the literature and reviewed for coverage, psychometric properties, validity, feasibility to implement, and clinical interpretability, according to International Society for Quality of Life Research (ISOQOL) guidelines [11]. All PROMs proposed for discussion were denoted as Grade A by the 5th International Consultation on Incontinence (ICI) [12]. PROM sets that covered all outcome domains of interest while minimizing question burden were then presented to the WG for discussion and voting. A similar process was followed to identify and define case-mix variables, and patient and procedural factors known to affect treatment outcomes for inclusion in the standard set.

\section{Patient validation surveys}

To ensure robust patient input, we solicited feedback via an anonymous online survey publicized via national continencerelated consumer organizations. The survey presented in lay terms outcome domains voted for inclusion by the WG. Respondents were asked to score those domains according to their importance on the GRADE scale and given an opportunity at the end of the survey to suggest any missing outcomes. The resulting suggestions were presented to the WG to inform their conclusions on the generalizability of the patient advisory group.

\section{Open review process}

To ensure transparency in the development process and allow input from stakeholders outside the formal WG, a 4-week open review period was held prior to the last WG teleconference. Key stakeholders identified by the project team, IUGA members, and individuals expressing interest in the measure set via the ICHOM website received an overview of the set, with links to the full detail reference guide and a feedback survey. Results of this survey were presented to the WG for discussion prior to set finalization.

\section{Results}

\section{Outcome domains and measures}

The literature search for outcome domains (Supplemental Material 1) identified 585 articles. An additional 11 articles were identified from other sources during the process. A title and/or abstract review was used for further refinement. A total of 184 articles were included for full-text review, and 39 were included in the final qualitative synthesis. After reviewing results of the literature search and patient discussion groups, the WG voted to include the following outcome domains in the standard set: symptom frequency and burden, physical functioning, interference with desired activities, emotional health, social interactions, sexual functioning, treatment burden, and overall satisfaction with the results of treatment. See Table 2 for a complete list of outcomes and outcome measures.

The International Consultation on Incontinence Questionnaire Overactive Bladder Module (ICIQ-OAB) is an eight-question instrument assessing the frequency of micturition, nocturia, urgency, and incontinence and the amount of bother caused by these symptoms [13, 14]. This PROM is validated for assessing $\mathrm{OAB}$, easy to complete, and free for use in clinical practice and routine outcome measurement and was therefore recommended by the WG.

The OAB-q, 26 questions of which form the ICIQ-OAB-q, is a well-validated and commonly used instrument to assess the effect of $\mathrm{OAB}$ on health-related QoL covering the domains of coping, concern, sleep, and social interactions. The WG felt that these domains mapped closely to the domains of physical functioning, interference with desired activities, emotional health, and social interactions that had been voted for inclusion in the standard set [15]. However, at 33 questions long, it was considered by the WG to be too lengthy for use in standard clinical practice. Instead, the 13-item short form of the OAB-Q (OAB-Q SF) was recommended [16].

The WG voted to measure sexual function with the six-item ICIQ Femala/Male Sexual Matters associated with Lower Urinary Tract Symptoms (FLUTS/MLUTSsex) as applicable according to gender $[14,17]$. The Treatment Benefit Scale (TBS), consisting of three questions assessing treatment efficacy, treatment tolerability, and overall satisfaction with treatment, was included to assess the domains of treatment benefit, burden, and satisfaction [18].

The resulting ICHOM standard set on OAB comprises 28 items. 
Table 2 Outcome domains and assessments in the standard set

\begin{tabular}{|c|c|c|c|}
\hline Category and outcome domain & Agreement $^{\mathrm{a}}$ & Outcome assessment & Agreement $^{\mathrm{a}}$ \\
\hline \multicolumn{4}{|l|}{ OAB symptom severity and burden } \\
\hline Frequency of OAB symptoms & 92 & Tracked via ICIQ-OAB & 83 \\
\hline Burden of OAB symptoms & 100 & Tracked via ICIQ-OAB & 83 \\
\hline \multicolumn{4}{|l|}{ Health-related quality of life } \\
\hline Physical functioning & 100 & Assessed via the OAB-Q SF & 85 \\
\hline Social impact & 88 & Assessed via the OAB-Q SF & 85 \\
\hline Emotional health & 100 & Assessed via the OAB-Q SF & 85 \\
\hline Interference with desired activities & 75 & Assessed via the OAB-Q SF & 85 \\
\hline Sexual functioning & 73 & $\begin{array}{l}\text { Assessed via the ICIQ-FLUTSsex } \\
\text { (women) or ICIQ-MLUTSsex } \\
\text { (men) }\end{array}$ & 83 \\
\hline Treatment benefit and tolerance & 82 & $\begin{array}{l}\text { My condition (urinary problems, } \\
\text { incontinence) has...(greatly } \\
\text { improved/improved/not } \\
\text { changed/worsened during } \\
\text { treatment). The tolerability } \\
\text { of my treatment for OAB is... } \\
\text { (inadequate, moderate, good, } \\
\text { excellent). }\end{array}$ & 77 \\
\hline Overall satisfaction with treatment & 100 & $\begin{array}{l}\text { My overall satisfaction is... } \\
\text { (extremely satisfied/very } \\
\text { satisfied/satisfied/not satisfied } \\
\text { with the treatment). }\end{array}$ & 77 \\
\hline
\end{tabular}

$I C I Q$ International Consultation on Incontinence Questionnaire, $O A B$ overactive bladder, $O A B-Q S F$ symptom bother and health-related quality of life (HRQL) questionnaire, FLUTS Female Sexual Matters associated with Lower Urinary Tract Symptoms, MLUTSsex Male Sexual Matters associated with Lower Urinary Tract Symptoms

${ }^{\text {a }}$ Percentage agreement among survey respondents (voting IN)

\section{Patient validation surveys}

Patient validation surveys revealed strong support for outcomes selected by the WG. A total of 99 complete responses to the survey was received from patients spanning a wide range of ages and treatment approaches; $76 \%$ of participants responded affirmatively to the question: "Do you feel this list captures the outcomes that matter or have mattered the most to you?" No major deficits in domain coverage were identified.

\section{Case-mix factors}

Demographic and medical history data that might affect patient treatment outcomes were included in the standard set to allow for risk-adjusted outcomes comparisons. See Table 3 for a complete list of the case-mix factors and definitions.

The WG voted to include only age and sex as demographic factors affecting $\mathrm{OAB}$ outcomes. Medications may have greater efficacy in patients $<65$ years of age [19-25], and women respond better to treatment than do men [21, 22, 26, 27].

Aspects of patients' medical history that may affect treatment outcomes or response to treatment included in the standard set were: body mass index (BMI), comorbid bowel conditions, pelvic organ prolapse (POP), enlarged prostate, history of prior pelvic surgeries, and diabetes or the metabolic syndrome. Women with higher BMI may be more likely to have urgency incontinence and increased symptom severity $[28,29]$. Studies suggest a link between OAB and irritable bowel syndrome or other bowel conditions, although how this affects treatment outcomes is less clear [30,31]. The association of $\mathrm{OAB}$ with anterior compartment prolapse resulted in the consensus to include POP [32]. As prostate conditions can increase storage symptoms, mimicking or worsening $\mathrm{OAB}$ and making treatment less successful, this condition was voted for inclusion in the case-mix factors [33, 34]. Histories of prior pelvic surgery were included due to reports of new-onset $\mathrm{OAB}$ following pelvic surgery [35]. Diabetes may exacerbate $\mathrm{OAB}$, which was also included [36-40]. The presence or absence of memory problems was also included; the WG felt that, on balance, cognitive impairment could alter outcomes despite the lack of supporting published evidence. Including a measure that asks patients if they have been told by a doctor that they have memory problems will allow further investigation into this issue.

Parity, mode of childbirth (vaginal versus Cesarean), and menopausal status were ultimately excluded due to lack of clear data on their relationship to OAB symptoms [41-50]. Current use of estrogens was included, as topical estrogen 
Table 3 Case-mix variable domains and definitions included in the standard set

\begin{tabular}{|c|c|c|c|}
\hline Category and case-mix factor domain & Agreement $^{\mathrm{a}}$ & Case-mix factor definition & Agreement ${ }^{\mathrm{a}}$ \\
\hline \multicolumn{4}{|l|}{ Demographic factors } \\
\hline Age & 100 & Year of birth & 93 \\
\hline Sex & 100 & Patient sex & 86 \\
\hline \multicolumn{4}{|l|}{ Baseline clinical factors } \\
\hline BMI & 85 & $\begin{array}{l}\text { How much do you weigh? (Weight in kgs or lbs). How tall are you? } \\
\text { (Height in cm or inches). }\end{array}$ & 100 \\
\hline Comorbid bowel condition & 71 & $\begin{array}{l}\text { Have you been told by your doctor or care provider that you have any } \\
\text { of the following? Tick all that apply. } 0=\text { None, } 2 \text { = Irritable bowel } \\
\text { syndrome, } 3 \text { = Inflammatory bower disease (Crohn's, ulcerative colitis). }\end{array}$ & 86 \\
\hline Diabetes & 77 & $\begin{array}{l}\text { Have you been told by your doctor or care provider that you have any } \\
\text { of the following? Tick all that apply. } 1 \text { = Diabetes. }\end{array}$ & 86 \\
\hline Cognitive impairment & 86 & $\begin{array}{l}\text { Have you been told by your doctor or care provider that you have any } \\
\text { of the following? Tick all that apply. } 4 \text { = A problem with your memory. }\end{array}$ & 86 \\
\hline Coexisting pelvic organ prolapse & 77 & $\begin{array}{l}\text { Do you have a feeling of a lump or "something coming down" or the need } \\
\text { to manually replace a prolapse in order to empty your bladder? }\end{array}$ & 93 \\
\hline Coexisting stress incontinence & 71 & $\begin{array}{l}\text { Do you leak urine with physical activity, coughing, laughing, or sneezing } \\
\text { or have you been told by a doctor that you have stress incontinence? }\end{array}$ & 92 \\
\hline $\mathrm{BPH}$ or prostatitis & 93 & $\begin{array}{l}\text { Have you been told by a doctor that you have a problem with your prostate? } \\
\text { Tick all that apply. } 0=\text { No, } 1=\text { Enlarged prostate or benign prostatic } \\
\text { hyperplasia (BHP), } 3=\text { Prostatitis. }\end{array}$ & 85 \\
\hline Current use of estrogens & 92 & $\begin{array}{l}\text { Are you currently taking estrogens or hormone replacement therapy by } \\
\text { mouth, a patch or cream on the skin, or as a suppository? }\end{array}$ & 92 \\
\hline History of pelvic surgery & 92 & $\begin{array}{l}\text { Have you had surgery to your pelvis? Please indicate what kind. } \\
\text { Female response options: } 0=\text { No; } 1=\text { Yes, surgery for stress urinary } \\
\text { incontinence; } 2=\text { Yes, prolapse surgery; } 3=\text { Yes, surgery to the rectum } \\
\text { or bowel; } 4=\text { Yes, hysterectomy; } 5=\text { Yes, other surgery. } \\
\text { Male response options: } 0=\text { No; } 1=\text { Yes, surgery to the rectum or bowel; } \\
2=\text { Yes, prostate surgery. }\end{array}$ & 92 \\
\hline Current $\mathrm{OAB}$ treatments & 100 & What are you currently using to treat your OAB symptoms? & 100 \\
\hline
\end{tabular}

$B M I$ body mass index, $B P H$ benign prostatic hyperplasia, $O A B$ overactive bladder

${ }^{a}$ Percentage agreement among survey respondents (voting IN)

has been shown to ameliorate $\mathrm{OAB}$ symptoms and systemic estrogen to be associated with worsening [51, 52].

Current $\mathrm{OAB}$ treatment is included in the standard set as an explanatory variable. By tracking patients' treatment in parallel with their outcomes and medical profiles will help identify particularly effective treatments for different patient populations.

The WG opted to collect all case-mix factors via patient reports to simplify implementation of the standard set. As all outcomes in the set are patient reported, all data are captured from a single source, streamlining data collection within the clinic and eliminating the need to integrate PROM data collection in electronic medical records (EMRs) or to align patient-reported and clinical data following collection.

\section{Initial data collection and follow up}

The standard set is designed for data collection to begin at the time of diagnosis, with follow-up at intervals defined by the treating clinician and to end at the time of patient-reported treatment success or loss to follow-up (Fig. 1). Baseline measures include both case-mix factors and all PROMs. Although studies suggest that baseline severity does not affect response to treatment, it may affect patient motivation to adhere to treatment and tolerate side effects $[53,54]$. All PROMs are collected at the time of diagnosis to calculate the effect of treatment over time.

Follow-up measures include all PROMs and explanatory variables. The WG recommended that follow-up surveys be completed as deemed appropriate by the treating clinician. Follow-up ends at patient-defined success, i.e., positive responses to the TBS questions and/or no further follow-up for 6 months. Subsequent presentations for treatment after 6 months are recorded as new episodes of care for the same patient. Treatment outcome is then defined as the difference in PROMs at patient-reported treatment success or the last available follow-up survey and baseline adjusted by relevant casemix factors.

\section{Discussion}

The ICHOM OAB WG aimed to develop a comprehensive, minimally burdensome, patient-centered, standard set of 
EXAMPLE 1: Follow-up continues every three months until either the treatment is successful and the patient is discharged from care or the patient is lost to follow-up

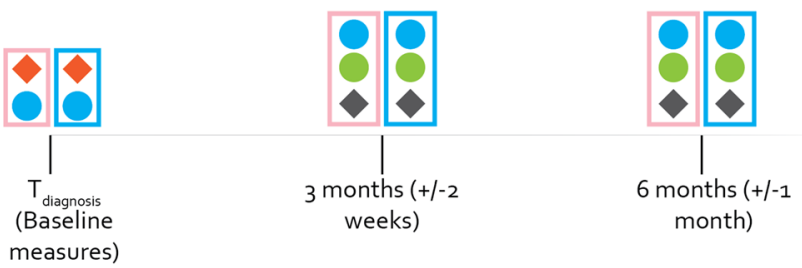

Case-mix factors

PROMs

Current treatment

Treatment satisfaction and tolerance

EXAMPLE 2: Subsequent presentation for treatment after 6 months would be recorded as a new episode of care for the same patient
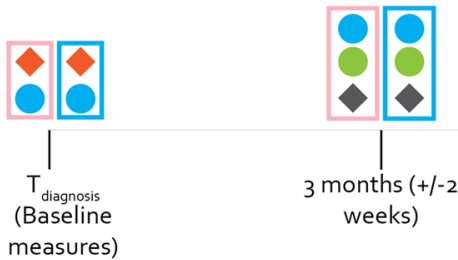

measures)
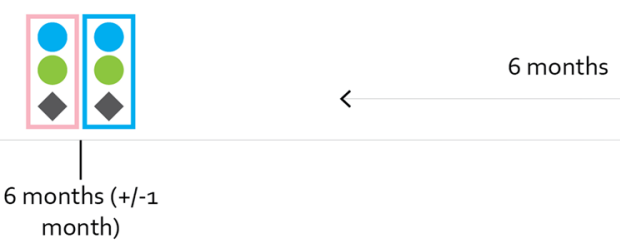

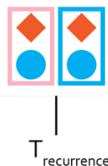

Female Baseline Measures (link)

Male Baseline Measures (link)

Female Follow-up (link)

Male Follow-up (link)

Fig. 1 Follow-Up timeline and sample questionnaires. The timeline illustrates when standard set variables should be collected from patients, clinicians, and administrative sources. Links to the sample questionnaires may be found in the legend below

outcome measures for evaluating the care of patients with OAB for use in routine clinical care. This led to the development of an outcome set that is efficient to collect and provides clinicians with a holistic view of treatment outcomes. This was accomplished by convening and guiding a WG of experts representing a broad range of stakeholders through a structured process, grounded in literature and expert opinion, to achieve consensus. Patients were included in the process to better determine what outcome domains mattered most to them. In addition, the WG limited its recommendation to measures that are free for use and broadly translated, allowing for set's adoption around the globe. All variables in the set are collected by patient report, and follow-up intervals are left to the clinician's discretion, as protocols may differ across specialties/countries. This allows for flexible data collection from the patient upon arrival at the clinic or remotely via mailed survey, patient portal, secure email, or app. It is important to note that the patient-reported case-mix factors were developed by the WG and therefore require further validation. To facilitate this validation and pilot the standard set as a whole, ICHOM supports members of the WG and other interested parties to implement the set and design validation studies. This work is overseen by a six-member steering committee, elected from the initial WG, that governs changes to the standard set over time.
The standard set was developed to have the lowest possible burden on patients and providers while collecting necessary data for comparison of outcomes. Thus, some measures discussed by the WG were not included in the final set: for example, a bladder diary (voiding diary) was not included to decrease the burden on patients of data collection. It was felt that tracking changes in symptom frequency and burden via the ICIQ-OAB adequately captured symptom severity and frequency.

In conclusion, this standard measure set provides meaningful, comparable, and easy-to-interpret measures for evaluating the care of patients with OAB. The inclusion of case-mix factors enables global comparisons of treatment outcomes across population groups. In time, it is anticipated/proposed that knowledge from these comparisons will encourage and empower providers to improve care and allow patients, providers, and payers to make informed decisions about their healthcare spending and treatment options.

Acknowledgements The authors would like to acknowledge the National Association for Continence (NAFC), the Canadian Continence Foundation (CCF), and Continence Foundation Australia (CFA) for their help in identifying patient advocates for participation in this project. We also thank Charles Shields, Jr., former Executive Director of IUGA for his unwavering support of this project and Elizabeth Olson for her support in preparing this manuscript. 
Sources of funding This work was developed by the International Consortium for Health Outcomes Measurement, a nonprofit organization based in Cambridge, Massachusetts. Sponsorship for this work was provided by the International Urogynecological Association (IUGA) through an unrestricted grant. IUGA had no control over the formation of the expert panel, the recommendations, or the submitted publication.

\section{Compliance with ethical standards}

Conflict of interest Dr. Stowell, Dr. Wissig, Dr. Foust-Wright and Ms. Olson were paid by ICHOM to support the development of this work. Dr. Gormley holds position of leadership at the American Urologic Association. Dr. Milsom has received paid travel expenses or honoraria from Allergan, Astellas, Pfizer, and SCA. Dr. Cardozo has received funding for research or lecturing for Astellas and Pfizer and for research consultancy and/or advisory work for Allergan, Astellas, BMR, Ferring, Pfizer \& Syner-Med. Dr. Cotterill has accepted payment for research from Astellas Pharma Europe BV and for consulting services from Procter and Gamble. Dr. Anger declares that she is an investigator for Boston Scientific Corporation and Astellas. Dr. Toozs-Hobson has received paid travel expenses or honoraria from Astellas, SEP, Pierre Fabre, Allergan, and Boston Scientific Corporation. Dr. Heesakkers has accepted paid travel expenses or honoraria or payment for research from Astellas, Allergan, Pierre Fabre, and Bluewind. No other conflicts of interest are reported.

Open Access This article is distributed under the terms of the Creative Commons Attribution 4.0 International License (http:// creativecommons.org/licenses/by/4.0/), which permits unrestricted use, distribution, and reproduction in any medium, provided you give appropriate credit to the original author(s) and the source, provide a link to the Creative Commons license, and indicate if changes were made.

\section{References}

1. Abrams P, Cardozo L, Fall M, et al. The standardisation of terminology in lower urinary tract function: Report from the Standardisation Subcommittee of the International Continence Society. Joint publication: Neurourol Urodyn. 2002;21(2):167178, Urology. 2003;61:37-49.

2. Haylen BT, de Ridder D, Freeman RM, et al. An international Urogynecological association (IUGA)/international continence society (ICS) joint report on the terminology for female pelvic floor dysfunction. Neurourol Urodyn. 2010;29(1):4-20. https://doi.org/ 10.1002/nau.20798.

3. Irwin DE, Milsom I, Hunskaar S, et al. Population-based survey of urinary incontinence, overactive bladder, and other lower urinary tract symptoms in five countries: results of the EPIC study. Eur Urol. 2006;50:1306-14.

4. Milsom I, Coyne KS, Nicholson S, et al. Global prevalence and economic burden of urgency urinary incontinence: a systematic review. Eur Urol. 2014;65(1):79-95. https://doi.org/10.1016/j. eururo.2013.08.031.

5. Stewart WF, Van Rooyen JB, Cundiff GW, et al. Prevalence and burden of overactive bladder in the United States. World J Urol. 2003;20:327-36

6. Irwin DE, Mungapen L, Milsom I, et al. The economic impact of overactive bladder syndrome in six western countries. BJU Int. 2009;103:202-9.

7. Porter ME, Lee TH. The strategy that will fix health care. Harvard Bus Rev. 2013;91:50-70.

8. Porter ME. What is value in health care? N Engl J Med. 2010;363: 2477-81. https://doi.org/10.1056/NEJMp1011024.
9. Pill J. The Delphi method: substance, context, a critique and an annotated bibliography. Socio Econ Plan Sci. 1971;5(1):57-71. https://doi.org/10.1016/0038-0121(71)90041-3.

10. Guyatt GH, Oxman AD, Kunz R, et al. GRADE guidelines: 2 . Framing the question and deciding on important outcomes. J Clin Epidemiol. 2011;64(4):395-400. https://doi.org/10.1016/j.jclinepi. 2010.09.012.

11. Cleary PD, Meterko M, Wright SM, Zaslavsky AM. Are comparisons of patient experience across hospitals fair? A study in veterans health administration hospitals. Med Care. 2014;52(7):619-25. https://doi.org/10.1161/HYPERTENSIONAHA.113.02854. Impact.

12. $5^{\text {th }}$ International Consultation on Incontinence. Editors Abrams, Cardozo, Kouhry and Wein. Health Publications Ltd, Paris 2013.

13. Donovan J, Abrams P, Peters T, et al. The ICS-'BPH' study: the psychometric validity and reliability of the ICSmale questionnaire. BJU. 1996;77:554-62.

14. Jackson S, Donovan J, Brookes S, et al. The Bristol female lower urinary tract symptoms questionnaire: development and psychometric testing. BJU. 1996;77:805-12.

15. Khullar V. Patient-reported outcomes and different approaches to urinary parameters in overactive bladder: what should we measure? Int Urogynecol J. 2012;23:179-92.

16. Coyne KS, Thompson CL, Lai JS, Sexton CC. An overactive bladder symptom and health-related quality of life short-form: validation of the OAB-q SF. Neurourol Urodyn. 2015;34(3):255-63.

17. Frankel S, Donovan J, Peters T, et al. Sexual dysfunction in men with lower urinary tract symptoms. J Clin Epidemiol. 1998;51(8): $677-85$.

18. Colman S, Chapple C, Nitti V, et al. Validation of treatment benefit scale for assessing subjective outcomes in treating overactive bladder. Female Urology. 2008;72(4):803-7. https://doi.org/10.1016/j. urology.2008.05.033.

19. Sand PK, Miklos J, Ritter H, Appell R. A comparison of extendedrelease oxybutynin and tolterodine for treating overactive bladder in women. Int Urogynecol J Pelvic Floor Dysfunct. 2004;15(4):243-8.

20. Steers W, Corcos J, Foote J, Kralidis G. An investigation of dose titration with darifenacin, an M3-selective receptor antagonist. BJU Int. 2005;95(4):580-6.

21. Layton D, Pearce G, Shakir S. Safety profile of tolterodine as used in general practice in England. Drug Saf. 2001;24(9):703-13.

22. Michel MC, Schneider T, Krege S, Goepel M. Does gender or age affect the efficacy and safety of tolterodine? J Urol. 2002;168(3): 1027-31.

23. Zinner NR, Mattiasson A, Stanton SL. Efficacy, safety, and tolerability of extended-release once-daily tolterodine treatment for overactive bladder in older versus younger patients. J Am Geriatr Soc. 2002;50(5):799-807.

24. Hill S, Elhilali M, Millard R, et al. Long-term darifenacin treatment for overactive bladder in patients aged 65 years and older. Curr Med Res Opin. 2007;23(11):2697-704.

25. Elinoff V, Bavendam T, Glasser DB, et al. Symptom specific efficacy of tolterodine extended release in patients with overactive bladder: the IMPACT trial. Int J Clin Pract. 2006;60(6):745-51.

26. Freeman R, Hill S, Millard R, et al. Reduced perception of urgency in treating overactive bladder with extended-release tolterodine. Obstet Gynecol. 2003;102(3):605-11.

27. Zinner N, Gittelman M, Harris R, et al. Trospium chloride improves overactive bladder symptoms: a multicenter phase III trial. J Urol. 2004;171(6 Pt 1):2311-5.

28. Swift S, Garely A, Dimpfl T, Payne C. A new once-daily formulation of tolterodine provides superior efficacy and is well tolerated in women with overactive bladder. Int Urogynecol J Pelvic Floor Dysfunct. 2003;14(1):50-5.

29. Khullar V, Sexton CC, Thompson CL, et al. The relationship between BMI and urinary incontinence subgroups: results from 
EpiLUTS. Neurourol Urodyn. 2014;33(4):392-9. https://doi.org/ 10.1002/nau.22428.

30. Matsumoto S, Hashizume K, Wada N, et al. Relationship between overactive bladder and irritable bowel syndrome: a large-scale internet survey in Japan using the overactive bladder symptom score and Rome III criteria. BJU Int. 2013;111(4):647-52.

31. Bulchandani S, Toozs-Hobson P, Parsons M, et al. Effect of anticholinergics on the overactive bladder and bowel domain of the electronic personal assessment questionnaire (ePAQ). Int Urogynecol J. 2015;26(4):533-7.

32. Salvatore $\mathrm{S}$, Serati M, Ghezzi F, et al. Efficacy of tolterodine in women with detrusor overactivity and anterior vaginal wall prolapse: is it the same? BJOG. 2007;114(11):1436-8.

33. Eckhardt MD, van Venrooij GE, Boon TA. Symptoms and quality of life versus age, prostate volume, and urodynamic parameters in 565 strictly selected men with lower urinary tract symptoms suggestive of benign prostatic hyperplasia. Urol. 2001;57(4):695-700.

34. Seki N, Yuki K, Takei M, et al. Analysis of the prognostic factors for overactive bladder symptoms following surgical treatment in patients with benign prostatic obstruction. Neurourol Urodyn. 2009;28(3):197-201.

35. De Boer TA, Kluivers KB, Withagen MI, et al. Predictive factors for overactive bladder symptoms after pelvic organ prolapse surgery. Int Urogynecol J. 2010;21(9):1143-9.

36. Chui A, Huang M, Wang C, Kuo H. Higher glycosylated hemoglobin levels increase the risk of overactive bladder syndrome in patients with type 2 diabetes mellitus. Int J of Urology. 2012;19(11): 995-1001.

37. Tubaro A. Defining overactive bladder: epidemiology and burden of disease. Urology. 2004;64:2-6.

38. Bunn F, Kirby M, Pinkney E, et al. Is there a link between overactive bladder and the metabolic syndrome in women? A systematic review of observational studies. Int J Clin Pract. 2015;69(2):199217.

39. Tai HC, Chung SD, Ho CH, et al. Metabolic syndrome components worsen lower urinary tract symptoms in women with type 2 diabetes. J Clin Endocrinol Metab. 2010;95(3):1143-50.

40. Karoli R, Bhat S, Fatima J, Priya S. A study of bladder dysfunction in women wit type 2 diabetes mellitus. Indian J Endocrinol Metab. 2014;18(4):552-7.

41. Coyne KS, Sexton CC, Irwin DE, et al. The impact of overactive bladder, incontinence and other lower urinary tract symptoms on quality of life, work productivity, sexuality and emotional well- being in men and women: results from the EPIC study. BJU Int. 2008;101:1388-95.

42. Bradley CS, Kennedy CM, Nygaard IE. Pelvic floor symptoms and lifestyle factors in older women. J Women's Health. 2005;14:128-36.

43. Parazinni F, Chiaffarino F, Lavezzari M, et al. Risk factors for stress, urge or mixed urinary incontinence in Italy. BJOG. 2003;110:927-33.

44. Tikkanen KA, Auvinen A, Tiitinen A, et al. Reproductive factors associated with nocturia and urinary urgency in women: a population-based study in Finland. Am J Obstet Gynecol. 2008;199(2):153.e1-12.

45. Lawrence JM, Lukacz ES, Nager CW, et al. Prevalence and cooccurrence of pelvic floor disorders in community-dwelling women. Obstet Gynecol. 2008;111(3):678-85.

46. Chuang FC, Kuo HC. Prevalence of lower urinary tract symptoms in indigenous and non-indigenous women in eastern Taiwan. J Formos Med Assoc. 2010;109(3):228-36.

47. Alling Möller L, Lose G, Jørgensen T. Risk factors for lower urinary tract symptoms in women 40 to 60 years of age. Obstet Gynecol. 2000;96:446-51.

48. Handa VL, Harvey L, Fox HE, Kjerulff KH. Parity and route of delivery: does cesarean delivery reduce bladder symptoms later in life? Am J Obstet Gynecol. 2004;191(2):463-9.

49. Zhang W, Song Y, He X, et al. Prevalence and risk factors of overactive bladder syndrome in Fuzhou Chinese women. Neurourol Urodyn. 2006;25(7):717-21.

50. Robinson D, Cardozo L, Milsom I, et al. Oestrogens and overactive bladder. Neurourol Urodyn. 2014;33(7):1086-91.

51. Tseng LH, Wang AC, Chang YL, et al. Randomized comparison of tolterodine with vaginal estrogen cream versus tolterodine alone for the treating postmenopausal women with overactive bladder syndrome. Neurourol Urodyn. 2009;28(1):47-51.

52. Cody JD, Jacobs ML, Richardson K, Moehrer B, Hextall A. Oestrogen therapy for urinary incontinence in post-menopausal women. The Cochrane database of systematic reviews. 2012;10: Cd001405.

53. Garely AD, Lucente V, Vapnek J, Smith N. Solifenacin for overactive bladder with incontinence: symptom bother and health-related quality of life outcomes. Ann Pharmacother. 2007;41(3):391-8.

54. Landis JR, Kaplan S, Swift S, Versi E. Efficacy of antimuscarinic therapy for overactive bladder with varying degrees of incontinence severity. J Urol. 2004;171(2 Pt 1):752-6. 